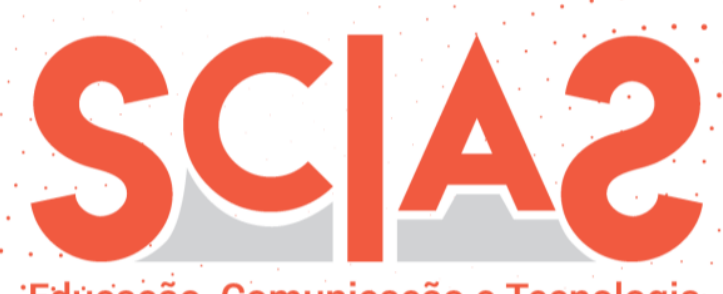

'Educuaçãa, Comunicação e Tecnologia

Atribuição BB CY 4.0

\title{
O (im)possível do educar na cibercultura: reflexões psicanalíticas sobre educação, tecnologia e os desafios da docência na contemporaneidade
}

\author{
Samuel Alcântara ${ }^{1}$ \\ Maria Celina Peixoto Lima ${ }^{2}$
}

\section{Resumo}

No campo da educação frequentemente nos deparamos com o mal-estar docente diante dos novos dispositivos tecnológicos que adentram as salas de aula, seja pelas mãos dos alunos, seja pela utilização de novas tecnologias aplicadas ao contexto educacional. Portanto, este estudo é uma investigação teórico-reflexiva acerca dos desafios da educação, incluindo professores e alunos, diante da cibercultura e da hiperconectividade contemporânea. Este trabalho apresenta uma discussão sobre as inovações tecnológicas vigentes na sociedade e suas vinculações com as dinâmicas e práticas pedagógicas, com base em contribuições de estudos em educação, filosofia, sociologia e psicanálise. Nesse contexto, a psicanálise, ao abrir espaço para a construção de um saber e para a produção de efeitos de significação num sujeito que, com isso, poderia transcender o lugar que lhe cabe no social e apontar na direção de seu desejo, parece oferecer algumas pistas para se pensar a relação entre a educação e as novas tecnologias.

\section{Palavras-chave}

Psicanálise. Educação. Docência. Tecnologia. Cibercultura.

Recebido em: 21/12/2018

Aprovado em: 11/09/2019

\footnotetext{
${ }^{1}$ Mestrando do PPG em Psicologia da Universidade de Fortaleza, Brasil.

E-mail: samuelalcantara@gmail.com

2 Professora titular do Programa de Pós-Graduação em Psicologia da Universidade de Fortaleza, Brasil.

E-mail: celina.lima@unifo.br
} 


\section{The (im)possible of educating in cyberculture: psycoanalytic reflections on education, technology and the challenges of teaching in the contemporaneity}

\section{Abstract}

In the field of education we often face teacher's malaise before the new technological devices that enter the classroom, either by the students' hands or by the use of new technologies applied to the educational context. Therefore, this study is a theoretical-reflexive investigation about the challenges of education, including teachers and students, in the face of cyberculture and contemporary hyper-connectivity. This work presents a discussion about current technological innovations in society and its links with dynamics and pedagogical practices, based on contributions of studies in education, philosophy, sociology and psychoanalysis. In this context, psychoanalysis, by opening space for the construction of a knowledge and for the production of effects of signification in a subject who could thereby transcend the place that belongs to him in the social and point in the direction of his desire, seems to offer some clues to think about the relationship between education and new technologies.

\section{Keywords}

Psychoanalysis. Education. Teaching. Technology. Cyberculture. 


\section{Introdução}

A experiência humana, ao longo dos tempos, foi atravessada pela relação direta entre apreensão e aplicação tecnológica. Desde o domínio do fogo, a manipulação da natureza pelo homo sapiens, através da técnica, trouxe significativas rupturas evolutivas que propiciaram a sobrevivência e o avanço da raça humana. Técnica vem do grego téchne, significando arte ou ciência, com isso, a técnica é um conjunto de regras, normas ou protocolos utilizados para atingir um determinado objetivo. Historicamente, a tecnologia desenvolvida pelo homem como técnica de dominação percorre o desenvolvimento das civilizações humanas há, aproximadamente, duzentos mil anos (KURZWEIL, 2014).

Cada um dos avanços tecnológicos que marca a historicidade do domínio da técnica pelo homem acontece em conjunto com uma série de transformações. A humanidade, como espécie, passa a evoluir em uma relação intrínseca com a tecnologia, com os avanços do domínio sobre a natureza e sobre a própria humanidade. $\mathrm{O}$ advento da linguagem e da escrita marcam o desenvolvimento de complexos sistemas de organização civilizatória-cultural, implicando diretamente nas relações humanas, que passam a expressar, ao longo do tempo, um conjunto de manifestações comuns àqueles indivíduos que habitam um mesmo espaço, sendo a educação um dos principais aspectos culturais da humanidade.

Também com a linguagem, a humanidade passa a sistematizar a observação técnica sobre a natureza e, através de ensaios mentais, a desenvolver métodos técnicos de apreensão e intervenção na realidade. Muitos são os pensadores e estudiosos que, no decorrer de dezenas de séculos, no oriente e no ocidente, mergulharam em seus arcabouços simbólico-linguísticos na tentativa de descrever a realidade das coisas e da experiência humana. Grandes nomes do pensamento ocidental, como Tales de Mileto, Sócrates, Platão, Copérnico, Descartes, Newton, Kant, Hegel, Darwin, Marx, Nietzsche, Freud, Einstein, dentre muitos outros, cada um em seu tempo, dedicaram suas vidas na árdua empreitada de observar e questionar a gênese dos fenômenos da natureza, 
aproximando o conhecimento observacional do conhecimento técnico e a ciência da tecnologia.

A contar da criação das primeiras ferramentas técnicas de caça à invenção dos ônibus espaciais, somos seres exploradores. De forma nômade, percorríamos os territórios, evoluindo nossa espécie. Desenvolvemos técnicas de navegação e exploração através dos oceanos, ganhamos os céus e estamos adentrando o espaço sideral em busca da conquista de novos planetas. Inclusive, com o avanço da tecnociência, foi criado um novo espaço, um ambiente de interação não físico-territorial, onde as relações e os lugares de exploração são tão ricos e prósperos quanto o espaço físico material que conhecemos, um multiverso de possibilidades digitais desenvolvidos por e para a técnica humana, um espaço cibernético - o ciberespaço.

Apesar de todo esse nítido avanço, a experiência nos mostra que, mesmo com o desenvolvimento progressivo da técnica, da ciência e do pensamento, algo na existência humana permanece fora de lugar. Na maior parte do tempo, então, nós sofremos e/ou tememos o possível sofrimento ocasionado pelas permanentes ameaças que pairam sobre nossa existência: o mal-estar. Freud (1930/2010) nos ensina que o processo de hominização surge para lidar com três fontes primordiais de sofrimento, a saber: a supremacia da natureza, a fragilidade do nosso corpo e a insuficiência das normas que regulam os vínculos recíprocos dos seres humanos, seja na família, no estado ou na sociedade.

Como Freud nos advertiu, o homem não é senhor em sua própria morada. A experiência humana não é definida pela objetividade da técnica, e sim pela subjetividade singular que atravessa os indivíduos diante das ameaças que as realidades operam e dos conflitos entre a economia psíquica e as realidades interna e externa. A realidade material sofre intervenções humanas relacionadas diretamente com a técnica na tentativa de controlar ameaças de sofrimento e de facilitar a experiência humana, implicando diretamente nos processos de subjetivação dos indivíduos. Contudo, algo sempre escapa à tentativa de controlar as fontes primordiais de sofrimento. O homem é, então, sujeito do inconsciente, feito do deslizamento de significantes que circunscrevem os laços 
humanos, como Lacan postulou. Então, o homem inventa técnicas de intervenção na natureza, no corpo e nas relações humanas, manuais de produção de conhecimento, de medicalização, de ensino, etc.

As transformações tecnológicas vividas na contemporaneidade representam não só a introdução de novos equipamentos em um discurso tecnocientífico, mas, principalmente, modificações e exacerbações de ordens sociais, culturais, de trabalho e educacionais. Os aparatos tecnológicos difundidos em nossa sociedade nos proporcionam, através da rede mundial de computadores, fonte inesgotável de informações e conhecimentos, de possibilidades de comunicação e relações humanas sem fronteiras físicas (RÜDIGER, 2016). Este contexto impacta diretamente na relação dos humanos com os mecanismos de educação, ensino e aprendizagem (LÉVY, 2010), bem como na produção de novas tecnologias que tentem suturar a incerteza humana diante da natureza, do corpo e das regras que regulam nossas relações.

Dispositivos da tecnologia da comunicação e informação (TIC), como smartphones e tablets, nos acompanham a todos os lugares, nos mantendo conectados 24 horas por dia na rede e com as pessoas em todo o mundo. $\mathrm{O}$ tempo também se altera quando, dependendo da velocidade da conexão, tudo é imediato e instantâneo. Como consequência, a espera se torna insuportável. As tecnologias digitais entraram em nossa existência de forma efetiva e, hoje, já não se imagina a vida sem elas, produzindo, inevitavelmente, efeitos importantes na condição do homem atual. Como observa Dunker (2017), tais efeitos surgem com uma superoferta de presença, caracterizando o isolamento e redução do laço social, a depressividade desejante, o déficit narrativo na construção de intimidade, a hipertrofia das expectativas narcísicas de reconhecimento, a intoxicação digital infantil, dentro outros sintomas que se revelam nos sujeitos e nas relações contemporâneas.

No campo da Educação, que nos surge como principal foco de interesse nessa discussão, frequentemente nos deparamos com o mal-estar docente diante dos novos dispositivos tecnológicos que adentram as salas de aula, seja pelas mãos dos alunos, seja pela utilização de novas tecnologias aplicadas ao contexto 
educacional. Não raro, os professores precisam competir com a tecnologia pela atenção de seus alunos numa luta que parece fadada ao fracasso; daí as discussões atuais sobre a utilização e aplicação de novas metodologias de ensino que prometem surgir como solução para a problemática da educação na contemporaneidade - e o que seriam tais metodologias, se não a própria aplicação de uma técnica sobre o "ser professor"?

No Brasil, como observa Prioste (2016), o acesso à internet e o uso de dispositivos tecnológicos têm sido cada vez mais estimulado por políticas públicas de inclusão digital. Nos grandes centros urbanos, crianças e adolescentes de diversas classes sociais exibem seus gadgets e podem ter acesso ao ciberespaço, seja nos ambientes escolares, nos telecentros comunitários, nas lanhouses populares ou em suas residências (PRIOSTE, 2016). Uma maior acessibilidade dos jovens brasileiros à internet poderia ser comemorada pelos profissionais de educação, se não fosse o fato de que suas principais atividades no ciberespaço ainda estão longe de serem educativas e, frequentemente, evolvem riscos.

É quase que consenso que o cenário educacional atual se configura de maneira bem peculiar: rendimento abaixo do esperado, baixa assiduidade e alto indicie de desinteresse. A esse cenário, acrescenta-se o preocupante índice de evasão escolar, que quintuplica no Ensino Médio (11,2\%) quando comparado aos anos iniciais do Ensino Fundamental (2,1\%) (INEP, 2017). Além sido, atualmente os professores lidam com fenômenos cada vez mais frequentes entre crianças e adolescentes: sérias situações de indisciplina, violência, condutas associais e, mais recentemente, o fenômeno das automutilações. Tais dificuldades, segundo Kupfer (2000), parecem se agravar com o fato de o docente não mais encontrar, no laço social, uma rede simbólica que dê suporte ao seu exercício profissional, passando a caber a ele, então, a tentativa hercúlea de sustentar, solitariamente, o lugar de referência e de representante da cultura que lhe foi outorgado ao longo dos séculos. Então, como podemos refletir acerca da disseminação de informação e da superoferta do outro proporcionada pelas novas tecnologias digitais no cenário educacional? 
Diante deste contexto, qualquer reflexão sobre o futuro dos sistemas educacionais e de formação docente deve ser fundada em uma análise prévia das mutações contemporâneas da relação com o saber (LÉVY, 2010). Mutações nos símbolos, equipamentos, organizações e meios de comunicação nos levam a refletir sobre a experiência da docência a partir do imbricamento social com as novas tecnologias, incluindo as digitais, frente à cibercultura e à aparente hiperconectividade. Já que, sentindo-se impotentesnessa tarefa e, em geral, cobrados a apresentar "resultados positivos" em avaliações externas - o que vem trazendo como consequência uma excessiva burocratização e automatização da docência - fica claro o mal-estar vivenciado diariamente pelos professores, que, ansiosos por momentos de formação, buscam, nos avanços da ciência e nas novas tecnologias voltadas à educação, algum amparo para a sustentação de sua prática.

Portanto, para compreender tais reflexões, este artigo surge como uma ampliação reflexiva de nosso trabalho apresentado no II Web Seminário Internacional em Educação e Tecnologia: Cultura Digital, promovido pela Faculdade de Educação da Universidade Estadual de Minas Gerais (UEMG) em 2017. Nosso trabalho tem como objetivo apresentar uma discussão sobre o ethoscontemporâneo, as inovações tecnológicas vigentes na sociedade e suas vinculações com as dinâmicas e práticas pedagógicas, com base em contribuições de estudos em educação, filosofia, sociologia e psicanálise. Nesse contexto, a psicanálise, ao abrir espaço para a construção de um saber e para a produção de efeitos de significação num sujeito que, com isso, poderia transcender o lugar que lhe cabe no social e apontar na direção de seu desejo, parece oferecer algumas pistas para se pensar a relação entre a educação e as novas tecnologias.

\section{Educação e tecnologia na contemporaneidade: uma exacerbação hipermoderna}

A modernidade é resultante, entre outros aspectos, da racionalidade iluminista e, portanto, da consolidação da racionalidade científica e tecnológica, que produziram o fenômeno da objetivação das coisas e da elevação da crença de que tudo pode ser explicado por essa mesma razão. A ideia de que a 
racionalidade e o progresso trariam a resposta para todos os dilemas sociais cria um sistema no qual as respostas são dadas com base em grandes narrativas e estruturas mais ou menos rígidas que organizam e problematizam a sociedade. A educação, estando inserida nesse contexto, reflete as características da própria sociedade, fomentando um discurso da organização do ensino e da aprendizagem como reflexão de demandas sociais e relações de trabalho (ARRUDA, 2009).

O século XX se foi e com ele a inversão de alguns paradigmas que funcionavam como alicerce da racionalidade moderna. O psicanalista Jorge Forbes (2012), por exemplo, nos chama atenção para o aspecto de que há hoje uma horizontalização das percepções racionais, diferentemente da primeira modernidade, a sociedade era "pai-orientada", organizada verticalmente, e o grande desafio era descobrir como chegar à diretoria, ao topo da pirâmide familiar ou profissional. Os sistemas educacionais eram a principal plataforma de produção desse fenômeno na primeira modernidade. Hoje, a questão é: aonde ir? O homem está desbussolado, ou seja, houve uma perda de referências que coincide com o advento da globalização, a chegada da segunda modernidade, a hipermodernidade.

No livro "Os Tempos Hipermodernos" (2004), Lipovetsky e Charles caracterizam hipermodernidade por um culto ao excesso, ao sempre mais. Segundo os autores, todas as coisas se tornam intensas e urgentes, o movimento é uma constante e as mudanças ocorrem em um ritmo frenético, determinando um tempo marcado pelo efêmero, no qual a flexibilidade e a fluidez aparecem como tentativas de acompanhar essa velocidade. Tudo é elevado à potência do mais, do maior. O capitalismo, a globalização e a hipermodernidade desvelam o paradoxo da contemporaneidade: a cultura do excesso.

Para tanto, as diferentes manifestações culturais, reconfiguradas através da internet pela desfronteirização, e todas as facilidades agregadas a velocidade que ela dispõe são características de uma nova revolução. Castells (2009) faz um paralelo importante da sociedade em rede como consequência da revolução das tecnologias de informação e comunicação, a rede como contraponto a 
verticalização implícita no início do século XX, o que ele chama de "a cultura da virtualidade real” (p.65), preconizando implicações acerca da comunicação mediada por computadores, do controle institucional, das redes sociais e das comunidades virtuais.

Um dos pioneiros a se debruçar sobre a fenomênica sociocultural advinda dos avanços tecnológicos e da globalização foi o filósofo Pierre Lévy. No livro Cibercultura (2010), o autor conceitua o processo cultural contemporâneo mediado pelas TICs como o conjunto de técnicas materiais e intelectuais, de práticas, de atitudes, de formas de pensamento e de valores, que prosperam acompanhados ao crescimento do ciberespaço, ou seja, o crescimento dos novos meios de comunicação que surgem com a World Wide Web. Na concepção de Lévy (2010), o ciberespaço é um rompimento paradigmático com o reinado da mídia de massa baseada na transmissão. Enquanto as mídias televisivas, radiofônicas e impressas efetuam sua distribuição para o receptor massificado, o ciberespaço permite às pessoas a comunicação personalizada, operativa e colaborativa em rede hipertextual.

Para Lévy (2010), a interconexão em tempo real é também a condição de existência de soluções práticas para os problemas de orientação e de aprendizagem no universo do saber em fluxo. Para o autor, o saber está na humanidade, é o que as pessoas sabem, de forma que todos sabem alguma coisa, ninguém sabe tudo e não existe um reservatório de conhecimento transcendental. Com isso, a conexão em tempo real possibilita que acontecimentos, decisões, ações e pessoas estejam situados em mapas dinâmicos de um contexto comum e transformem continuamente o universo virtual em que adquirem sentidos, modificando assim a relação com o saber. Portanto, toda técnica produzida na hipermodernidade é difundida através do aparato comunicacional das TICs. "Tudo" passa a ter uma solução, um remédio, basta dar um google.

Por outro lado, Castells (2003) afirma que "a internet é, de fato, uma tecnologia da liberdade, mas pode libertar os poderosos para oprimir os desinformados, pode levar à exclusão dos desvalorizados pelos conquistadores do valor" (p.225). 
Essa dicotomia apresentada é perceptível a partir da relação da humanidade com o desenvolvimento tecnológico na hipermodernidade. Tal desenvolvimento propicia mutações, como já introduzimos, constantes e aceleradas nos símbolos, equipamentos, organizações e meios de comunicação, podendo, por consequência, influenciar grandes espaços até então impenetráveis. Ou seja, ao mesmo tempo que as tecnologias de informação e comunicação têm uma função de excepcional importância ao diminuir o espaço físico/geográfico para a difusão de informações e produção do conhecimento, parecem não traduzir a efetiva construção de saber e conhecimento, deflagrando o importante papel do professor nessa tarefa.

Neste sentido, com as TICs, há uma modulação dos laços sociais, onde a escola, uma vez que é local de formação das novas gerações, reproduz propriedades intrínsecas a sociedade. Para Martins (2014), o processo de formação dos professores, por sua vez, não se dá num vácuo social, se inserindo no âmbito do conjunto de demandas instituídas pela própria sociedade, já que são esses os profissionais que contribuirão para a formação acadêmica dos indivíduos, possibilitando-lhes o acesso ao universo dos conhecimentos sistematizados. Ou seja, o oposto da enxurrada de informação que os dispositivos tecnológicos nos entregam.

Arruda (2009) relata que há um discurso vigente sobre uma "nova postura" do professor ante as novas tecnologias educacionais, como seu novo papel de “orientador" dos alunos em sua busca pelo conhecimento. Mas considera-se que essa realidade apresentada à escola, com a inserção das novas tecnologias digitais, não representa apenas outra postura do profissional da educação perante o conhecimento desenvolvido com seus alunos, representa profunda ruptura com as formas anteriores de ensino/aprendizagem. Segundo o autor, a informática e a internet trazem consigo uma nova lógica e postura diante da aprendizagem completamente distinta das anteriores, afinal, a relação estrutural da escola não se estende para além dos muros, ao passo que no ciberespaço as possibilidades comunicativas e de formação são exuberantes. 
Sendo assim, ao abordar a influência da cibercultura na educação, Lévy (2010) afirma que o ponto principal em relação ao novo papel dos professores é:

\begin{abstract}
A mudança qualitativa nos processos de aprendizagem. Procura-se menos transferir cursos clássicos para formatos hipermídia interativos ou "abolir a distância" do que estabelecer novos paradigmas de aquisição dos conhecimentos e de constituição dos saberes (p.173).
\end{abstract}

Para o autor, a direção mais promissora, traduzindo a perspectiva de uma aprendizagem e inteligência coletiva no domínio educativo, é a aprendizagem cooperativa. Esta visão de Lévy (2010) reflete o seu otimismo quanto ao avanço dos sistemas de Educação a Distância (EAD), uma forte realidade na educação básica e superior no Brasil.

Além da facilidade de acesso e distribuição da informação, questões econômicas envolvem o uso da EAD. Bruno (2009) coloca que a escolha por essa modalidade de ensino é "mais barata", atendendo uma grande demanda de estudantes, priorizando a quantidade no lugar da qualidade. As críticas do autor fazem parte de seu estudo em direção a construção de uma didática on-line, que segundo ele, o uso de recursos multimídia não asseguram a aprendizagem. A apreensão dos dispositivos tecnológicos deve refletir uma coerência didáticopedagógica. Um novo posicionamento do educador na construção do laço com o educando, uma abordagem estar junto virtual que ofereça à relação professoraluno e aluno-alunos uma constante construção por via do acompanhamento, da intervenção, da orientação, da colaboração e da integração, que pode ser traduzida em termos psicanalíticos por desejo e transferência, fomentando a relação com a aprendizagem.

Com tudo, uma questão nos inquire: se a desbussolização do homem é uma característica da hipermodernidade, como navegar na infinitude informacional do ciberespaço sem se perder? Afinal, ao impossível devemos estar sempre advertidos. 


\section{O (im)possível do educar: psicanálise e educação}

"Em um primeiro estádio, aceitei o bonmot que estabelece existirem três profissões impossíveis - educar, curar e governar -, e eu já estava inteiramente ocupado com a segunda delas". (FREUD, 1937/2006, p. 341). Portanto, educar é um dos três ofícios definidos por Freud como práticas impossíveis. Impossível, entretanto, não é utilizado como sinônimo de "impraticável", muito menos faz alusão a uma inevitável paralisação diante do que não se pode avançar, ou seja, do que as iniciativas não podem fazer mais que prestarem-se à hesitação. $\mathrm{O}$ termo, aqui, refere-se ao fato de o empreendimento educativo não garantir um bom e regular desempenho das ações do profissional que a ele se dispõe. $\mathrm{O}$ ato de educar se constitui, também, pelo fracasso, já que a técnica não é capaz de excluir o insucesso. $\mathrm{O}$ não reconhecimento desse caráter tende a levar o professor a experimentá-lo como impotência.

Mas entre a impossibilidade, oriunda do sistema aristotélico da lógica modal, que versa sobre o necessário, o impossível, o possível e o contingente, recuperada por Freud com base nas premissas kantianas das profissões impossíveis, e a ideia de impotência, introduzida pela estrutura lógica lacaniana para se opor (e realçar) à anterior, há um salto fundamental que nos convém examinar (PEREIRA, 2013, p. 487).

No âmbito educacional, tanto impotência quando impossibilidade podem ser tomadas como representação do mal-estar docente, porém, engendrando efeitos diferentes. Pela via da impotência, onde a verdade que o discurso enuncia é contradita ou contestada por seu efeito, fazendo emergir o sentimento de insuficiência diante do qual não há mesmo o que se possa fazer, e, por outro lado, seguindo a impossibilidade, o discurso dependeria daquilo que lhe é imprevisível ou contingente, sendo necessário, portanto, admitir uma cota de fracasso inerente ao educar (PEREIRA, 2013).

É através da noção de impotência que aqui podemos circunscrever um importante núcleo em nossa reflexão. Afinal, que verdade é essa que, como efeito de sua própria enunciação, é contestada, desamparando e desautorizando o professor ali onde o seu ato se faria operar? O professor fala de um lugar de saber e, ao falar, crê-se ilusoriamente sem falhas, mestre daquilo que diz (GUTIERRA, 2002). Nessa posição discursiva, que implica num não 
aparecimento do sujeito da castração, ele apresenta-se diante do aluno como "Todo", e essa é a verdade que, ao se pretender absoluta, o desampara por não admitir a cota de impossibilidade do ato educativo.

Mesmo que Freud não tenha publicado um texto específico sobre educação, a temática sempre esteve presente em seu pensamento. No texto "O futuro de uma ilusão" (1927/2014), considerado, por muitos, seu tratado pedagógico, Freud afirma que a educação tem por finalidade a instauração do princípio de realidade, permitindo que a criança possa renunciar a sua modalidade de funcionamento primeva, quase toda submetida ao princípio do prazer.

Consequentemente, educar, como um ato, se refere ao registro de inscrições, de marcas que operam a passagem de pura satisfação das pulsões para um universo simbólico onde a lei, representada pela palavra do Outro, introduz o futuro sujeito ao "civilizado". Dessa forma, é possível afirmar que todo ato educativo refere-se a "operações de uma transmissão - de um legado, de um saber, de um desejo -, e de transformação - da carne, ao sujeito, a operação da castração" (MARIOTTO, 2017, p. 36).

A relação da psicanálise com a educação sempre atravessou alguma resistência no meio psicanalítico, já que a psicanálise trata o saber como pertencente a singularidade do sujeito e a educação pedagógica trata o saber a partir de uma transmissão de discurso. Então, para Freud, sujeitar, educar e curar a categoria de profissão impossível já é um enorme motivo para que os psicanalistas se debrucem sobre essa similaridade, porém:

Sempre com o compromisso ético de vislumbrarem o abismo que separa a posição do analista e o lugar do educador. Isto é, se por um lado, tanto educar quanto psicanalisar leva o praticante à dura constatação de que não se educa tudo nem se cura tudo, por outro, o lugar de onde se faz operar esse impossível é completamente distinto um do outro (MARIOTTO, 2017, p. 37).

No texto "Observações sobre o amor de transferência" (1915/2010), Freud, além de já ter elevado o conceito de transferência ao status de principal engrenagem do tratamento psicanalítico, coloca este conceito como a reprodução dos clichês e das inscrições traumáticas do sujeito, que reedita os impulsos e fantasias 
despertadas e tornadas conscientes durante o desenvolvimento da análise, trazendo como singularidade a substituição de uma pessoa anterior pela pessoa do psicanalista.

Mariotto (2017) destaca que a ideia de figura que pode ser a substituta nessa operação transferencial é o professor. Assim, o professor é convocado a ocupar um lugar que transcende a prática pedagógica, na medida em que se torna suporte dos investimentos desejantes de seu aluno, já que é objeto de uma transferência. Mais além da figura pessoal do professor, o educador vai representar, para o aluno, uma função. Substitui, nesse momento, as figuras parentais e/ou pessoas que lhe foram importantes, representando então esse lugar de saber, de idealização e de poder. Implica, portanto, em uma relação afetiva e, por isso, sempre ambivalente.

Assim, para Freud, educar é transferir um legado de pai para filho, uma passagem de experiência entre um adulto e um jovem. Partindo da premissa de que a relação pedagógica está implícita no processo civilizatório humano, a educação se desenvolve muito mais pelo laço social que se estabelece do que pelo conhecimento adquirido que expressamos ao outro. Contudo, parece-nos que as revoluções tecnológicas portáteis, sistemas de busca da internet como o Google, as redes sociais digitais como Facebook e os aplicativos de mensagem instantânea como Whatsapp, produzem uma inversão paradigmática na tríade professor-saber-aluno.A desbussolização do homem na hipermodernidade que Forbes (2012) trata atinge em cheio a atual percepção da desvalorização do professor. Bem como a queda da sua autoridade como mestre de um saber diante das ciências do ensino e a dessacralização da escola vêm impedindo que o docente encontre, no social, uma rede simbólica que dê sustentação ao seu exercício profissional.

Para Mariotto (2017), aprender supõe sempre aprender com alguém. Sendo assim, esse que ensina será sempre colocado pelo aluno numa determinada posição que pode ou não proporcionar a aprendizagem, indicando que o lugar que o aluno o coloca não é apenas o daquele que ensina. É o desejo inconsciente 
desse aluno que está determinando o lugar a ele conferido, como uma espécie de tela onde serão depositadas projeções alheias a ele enquanto pessoa.

E o que podemos pensar quando essa mediação projetiva é realizada materialmente por uma tela de polímero de silício? Há que se levar em consideração, ainda, que o jovem apresenta um "saber em excesso" que o adulto/professor já recalcou. Estando advertido da falácia da suposta completude prometida na infância, desconfia dos ideais transmitidos pela cultura e dos seus representantes no mundo adulto - pais e professores -; e, sabendo da impossibilidade de se chegar a um saber ideal e absoluto, não raro, desnuda o professor que insiste em apresentar-se como detentor de um saber sem falhas (GUTIERRA, 2003). Nesse contexto, que esperam, então, os jovens alunos de seus mestres? Podem os professores assumir a tarefa da transmissão de um desejo de saber à juventude, como propunha Freud, diante de tal desautorização de seu lugar?

A inversão paradigmática da cultura do excesso preconizada pela hipermodernidade parece deflagrar ainda mais a impotência do docente quanto ao "tudo saber". A internet, como concentração hipertextual da informação (LÉVY, 2010), acentua a impossibilidade do educador de manejar toda a informação.

Lacan (2005), nos adverte que "as pessoas não percebem muito bem o que querem fazer quando educam [...] e são tomadas pela angústia quando pensam no que consiste educar" (p. 58). Freud (1910/2006), por sua vez, afirma que "uma escola secundária deve conseguir mais do que não impelir seus alunos ao suicídio. Ela deve lhes dar o desejo de viver" (p. 243). Entre o oferecimento de condições de possibilidade para a emergência de um "desejo de viver" e a angústia do não perceber como fazê-lo, é que se encontra o professor. É o possível diante do impossível abismo, que se acentua entre a informação e o conhecimento produzidos pela cibercultura, na propagação experiencial de um tempo de assimilação simbólica do saber. 


\section{A técnica, a cultura digital e os desafios da docência: há solução possível?}

Diante das incertezas do educar, da violência presente nas escolas, das tentativas de suicídio dos alunos, da proliferação de diagnósticos em saúde mental, da consequente entrada da indústria farmacológica nas salas de aula e da mediação discursiva produzida pelo mundo digital, o professor precisa construir modos de fazer operar seu ato frente a um sujeito que, marcado pelo discurso capitalista, é nivelado à condição de objeto (PEREIRA, 2013); mas se, por um lado, o aluno é objetalizado por um saber tecnocientífico - que atravessa a pedagogia, se propondo, geralmente sem êxito, a ensinar o professor a exercer sua profissão -, por outro, é induzido ele próprio ao consumo ilimitado de objetos, obedecendo aos imperativos do ter para não ser segregado.

Baseados em dados estatísticos, funcionam como instrumento norteador para a aplicação de tecnologias cada vez mais específicas e objetivas: uma medicalização exata, uma psicologia pontual ou uma pedagogia sem falhas (PEREIRA, 2013). A informação que atravessa os gadgets é fonte de massificação de técnicas de controle e poder. O paralelo tecnológico que pulveriza a construção e disseminação de informação, produz um déficit narrativo na construção dos laços sociais (DUNKER, 2017), deflagrando nos profissionais docentes a busca desenfreada por técnicas que resolvam o problema da falta de interesse e dispersão dos alunos, seja pelo uso exacerbado de dispositivos tecnológicos ou não.

Na escola, não são poucas as queixas, como já expomos, em relação a falta de interesse dos alunos, "sem educação", como coloca Prioste (2016). Segundo a autora, em meio ao uso desenfreado da internet e dos dispositivos tecnológicos digitais, alunos vêm apresentando dificuldades de atenção e defasagens na aprendizagem. Prioste (2016) enfatiza, ainda, que não são poucas as reclamações concernentes à hiperatividade, ao excesso de impulsividade, de irritabilidade e de violência, assim como problemas relacionados às compulsões por jogos, internet, dentre outras. 
Dunker (2017) nos traz menções diagnósticas das narrativas de sofrimento do nosso tempo a partir do modo de vida digital que, por consequência, nos leva a pensar nas implicações de tais sintomas na busca tentadora por respostas em manuais descritivos, classificatórios e técnicos. Parece improvável que estejamos vivendo formações sintomáticas específicas com o uso exacerbado e intoxicante da vida digital, "os sintomas serão provavelmente difusos e a epidemia virá sem que entendamos seu processo de transmissão" (p. 119).

Desse modo, Dunker afirma que "a intoxicação digital crônica é uma patologia discursiva" (2017, p. 119), ou seja, deve ser entendida simultaneamente como uma alteração do laço social e da relação de reconhecimento. Ora, se a psicanálise estabelece que a relação pedagógica, como vimos, está implícita na transferência com um outro, ocupado pela figura do professor em substituição ao pai e se a educação se desenvolve muito mais pelo laço social que se estabelece do que pelo conhecimento adquirido que expressamos ao outro, a cibercultura, e as tecnologias que dela provém, parecem fragilizar a projeção de reconhecimento do outro como detentor de um saber, de algo a ser transmitido. Afinal, "dá um Google" que "tudo se acha".

Dunker (2017) caracteriza a vida no digital por três posições ou disposições subjetivas. $\mathrm{O}$ aumento da velocidade das demandas, ou seja, trocas e acesso fácil à informações; a superficialidade dos contatos interpessoais, com a redução da espessura imaginaria da vida fantasística e o correlato aumento de sua extensão; e a introdução de práticas que substituem o conflito, como "a evitação situacional por meio da exclusão, invisibilidade ou indiferença” (p. 121). A hipótese do autor é que a intoxicação digital decorre de uma nova moral sexual civilizada que altera difusamente práticas sociais e o uso da linguagem. Sendo assim, há um problema na demanda do sujeito causada pelo anonimato calculado do discurso digital, sendo identificada como uma depressivização do desejo (DUNKER, 2017). Incluímos aqui o desejo de saber, que difere do afogamento no mar de informações.

É essa a lógica que vem dando corpo à relação professor/aluno e à formação docente na atualidade. O contraponto entre uma desregulação dos laços 
mediadas por dispositivos tecnológicos de um lado e técnicas de intervenção que desresponsabilizam o docente em seu saber-fazer do outro. Segundo Nóvoa (2011), nesse campo, houve um deslocamento de um modelo formativo baseado no protagonismo docente e em seus recursos para a construção de um saber, em direção a uma "indústria do ensino", pautada num conjunto de novos conhecimentos articulados por especialistas, que circulam em manuais pedagógicos e tecnologias digitais voltadas à educação. Essa mudança, afirma o autor, traz como efeito a sensação de eterna desatualização e, embora cresça o incentivo no setor, o modelo formativo continua seguindo o padrão tradicional: seminários, palestras e aulas à distância, todos pautados na lógica da informação, que não consegue oferecer suporte ao professor, frente às urgências complexas e ambíguas da experiência do educar.

Por tanto, levando em consideração o ofício docente na hipermodernidade e as características que permeiam nossa cultura imbricada com as tecnologias digitais, é aí que se situa o ponto nodal de nossa problematização: os professores que, desamparados em sua profissão e submetidos a uma lógica objetalizante, recorrem, sob o marco de suas impotências, a manuais tecnopedagógicos, que tentam foracluir o impossível do educar. É na aposta no saber produzido pelo próprio professor no encontro com seus pares que avançamos nossa reflexão, a partir de uma torção que o conduza da aplicação de tecnologias pedagógicas produzidas por cientistas em direção ao comprometimento crítico e político com suas práticas.

\section{Em busca de considerações finais}

À guisa de conclusão, tratar de um assunto tão flexível, ainda inacabado, é incorrer no risco de analisar processos que talvez não se configurem na realidade social. Ainda assim, percebe-se ser importante dar voz a essas discussões de maneira a problematizar e a contribuir analiticamente para esse campo de estudos. Afinal, as tecnologias da cibercultura transformam a vida de todos nós, envolvidos diretamente ou indiretamente com elas. 
Na educação, percebe-se a necessidade de contribuições teóricas nos vários campos que permeiam a educação, incluindo a extraterritorialidade da psicanálise, de maneira a permitir um olhar mais aprofundado sobre a dinâmica do desenvolvimento tecnológico e suas respectivas relações com a informação, o conhecimento e a experiência do saber.

A apreensão dos possíveis efeitos da cibercultura na constituição subjetiva dos jovens sob a perspectiva psicanalítica demanda uma análise do debate que envolve a hipótese de uma nova economia psíquica engendrada nas transformações políticas e socioeconômicas das últimas décadas. Se na época de Freud chamou-lhe a atenção o mal-estar da cultura relacionado à repressão da sexualidade e à culpa pelos desejos proibidos que insistentemente se manifestavam, no momento atual, com o estímulo à liberação das pulsões sexuais em direção ao consumo, impera o mal-estar do desejo com todas as sintomáticas de seus excessos, de um lado, e de seus déficits, de outro.

A crença na pujança reflexiva de nosso empreendimento decorre da essência clássica que atravessa a história da educação em nossa civilização: uma "especial posição subjetiva” (GUTIERRA, 2002) dos mestres que conseguem cumprir com algum sucesso a função educativa. Esses profissionais não só devem fazer furo nos "saberes absolutos" que perpassam o campo da educação, como, a partir do seu saber-fazer, devem construir alguma borda, dando sustentação ao seu ato. Tal posicionamento, no entanto, não parece passível de um ensino objetivo, mas, certamente, aponta para a possibilidade de uma transmissão contínua e politizada, ao sabor dos acontecimentos.

Por fim, é preciso enfatizar, mais uma vez, que a psicanálise sustenta que o sujeito é efeito de identificações. Em nossos tempos hipermodernos onde para tudo se pretende uma explicação e uma resposta eficaz, aqui nós frustramos a lógica hegemônica. Não trazemos uma solução prêt-à-porter, mas buscamos interrogar e implicar o sujeito em sua relação com a educação e as novas tecnologias contemporâneas. Por tanto, como aparato teórico-clínico, a psicanálise pode ter algo a dizer sobre o multiverso paralelo de possibilidades que cibercultura inaugurou. A construção de outros espaços de conhecimento, 
de outras territorialidades, é o grande desafio posto pela contemporaneidade aos sistemas educacionais. Estejamos atentos e apostemos. 


\section{Referências}

ARRUDA, E. Relações entre tecnologias digitais e educação: perspectivas para a compreensão da aprendizagem escolar contemporânea. In: FREITAS, M. T. D. A. (Org.). Cibercultura e formação de professores. Belo Horizonte: Autêntica, 2009.

BRASIL. Ministério da Educação. Instituto Nacional de Estudos e Pesquisas Educacionais Anísio

Teixeira. Diretoria de Estudos Educacionais. Indicadores de fluxo escolar da educação básica.

Brasília: MEC, 2017.

BRUNO, A. R. Aprendizagem do adulto: contribuições para a construção de uma didática on-line. In: FREITAS, M. T. D. A. (Org.). Cibercultura e formação de professores. Belo Horizonte: Autêntica, 2009.

CASTELLS, M. A galáxia da internet: reflexões sobre a internet, os negócios e a sociedade. Rio de Janeiro: Zahar, 2003.

CASTELLS, M. A sociedade em rede. Rio de Janeiro: Paz e Terra, 2009.

DUNKER, C. Intoxicação digital infantil. In: BAPTISTA, A.; JERUSALINSKY, J. Intoxicações eletrônicas: o sujeito na era das relações virtuais. Salvador:

Álgama, 2017. p. 117-145.

FORBES, J. Inconsciente e Responsabilidade: Psicanálise do Século XXI.

Barueri, SP: Manole, 2012.

FREUD, S. Contribuições para uma discussão acerca do suicídio. In: Edição Standard Brasileira

das Obras Psicológicas Completas de Sigmund Freud. Vol. XI. Rio de Janeiro: Imago, 1910/2006.

Análise terminável e interminável. In: Edição Standard Brasileira

das Obras Psicológicas

Completas de Sigmund Freud. Vol. XXIII Rio de Janeiro: Imago, 1937/2006. . Observações sobre o amor de transferência. In: FREUD, S. Obras

completas. São Paulo: Companhia das Letras, v. 10, 1915/2010. . O mal-estar na civilização. In: Obras completas. São Paulo:

Companhia das Letras, v. 18, 1930/2010. p. 13-122. . O futuro de uma ilusão. In: . Obras completas. São Paulo:

Companhia das Letras, v. 17, 1927/2014.

GUTIERRA, B. C. C. O mestre (im)possível de adolescentes - uma especial posição subjetiva na

transmissão. Estilos da Clínica, 7(12), 36-47, 2002.

. Adolescência, psicanálise e educação: o mestre "possível" de

adolescentes. São Paulo:

Avercamp, 2003.

KUPFER, M. C. M. Educação para o futuro: Psicanálise e Educação. São Paulo:

Escuta, 2000.

KURZWEIL, R. Como criar uma mente: os segredos do pensamento humano.

São Paulo: Aleph, 2014.

LÉVY, P. Cibercultura. 3. ed. São Paulo: Editora 34, 2010.

LIPOVETSKY, G.; CHARLES, S. Os tempos hipermodernos. São Paulo:

Barcarolla, 2004.

MARIOTTO, R. M. M. Algumas contribuições da psicanálise à educação a partir dos conceitos de transferência e discurso. Educar em Revista, Curitiba, v. 64, p. 35-48, Abril/Junho 2017. 
MARTINS, J. B. A formação de professores no âmbito da abordagem. Revista Quadrimestral da Associação Brasileira de Psicologia Escolar e Educacional, São Paulo, v. 18, n. 3, p. 467-476, Setembro/Dezembro 2014.

NÓVOA, A. et al. Pesquisa em educação como processo dinâmico, aberto e imaginativo: uma

entrevista com António Nóvoa. Educação e Realidade. Porto Alegre: UFRGS/FACED, 36(2),

2011.

PEREIRA, M. R. Os profissionais do impossível. Educação \& Realidade, 38(2), 2013.

PRIOSTE, C. $O$ adolescente e a internet: laços e embaraços no mundo virtual.

São Paulo:

Edusp, 2016.

RÜDIGER, F. As teorias da cibercultura: perspectivas, questões e autores. $2^{\mathrm{a}}$. ed. Porto Alegre:

Sulina, 2016. 